\title{
Hypercholesterolaemic Serum Increases the Permeability of Endothelial Cells through Zonula Occludens-1 with Phosphatidylinositol 3-Kinase Signaling Pathway
}

\author{
Chang Bian, Geng Xu, Jianan Wang, Ji Ma, MeiXiang Xiang, and Peng Chen \\ Department of Cardiology, Second Affiliated Hospital, Zhejiang University School of Medicine, Hangzhou 310009, China
}

Correspondence should be addressed to Peng Chen, skyoutwin@yahoo.com.cn

Received 15 June 2009; Accepted 4 November 2009

Recommended by Omar Benzakour

Purpose. Hypercholesterolemia and tight junctions play important roles in atherosclerosis. But the relationship between these two factors is unclear. In the present study, we investigated whether hypercholesterolemic serum could change the permeability of endothelial cells through altering expression and/or distribution of tight junction protein zonula occludens-1 (ZO-1). Phosphatidylinositol 3-kinase (PI3K) signaling pathway was also examined. Materials and Methods. Cultured endothelial cells were treated with different concentration levels of hypercholesterolemic serum. The expression and distribution of ZO-1, the permeability of cultured cells and the involvement of PI3K signaling pathway were measured by various methods. Results. In the present study, we found that hypercholesterolemic serum could not change the expression of ZO-1 either in mRNA or protein level. However, hypercholesterolemic serum could change the distribution of ZO-1 in cultured endothelial cells, and increase the permeability with a dose-dependent manner. When PI3K specific inhibitor wortmannin was used, the effects induced by hypercholesterolemic serum could be partly reversed. The role of PI3K signaling pathway was further confirmed by PI3K activity assay. Conclusions. Our results suggested that although hypercholesterolemic serum could not change the expression of ZO-1, it could change the distribution and increase the permeability in endothelial cells through PI3K signaling pathway.

Copyright () 2009 Chang Bian et al. This is an open access article distributed under the Creative Commons Attribution License, which permits unrestricted use, distribution, and reproduction in any medium, provided the original work is properly cited.

\section{Introduction}

Elevated permeability of endothelium is crucial in atherosclerosis because it allows circulating lipoproteins and inflammatory cells to infiltrate into intima. The barrier function is maintained partially by tight junctions between adjacent endothelial cells [1]. Zonula occludens-1 (ZO-1) plays an important role in binding occludin to cytoarchitecture [2] and regulating cellular permeability [3]. Hypercholesterolemia is known as a major risk factor for atherosclerosis. However, whether hypercholesterolemic serum can lead to atherosclerosis through influencing cell junctions is still unclear. So in this study, we investigated the effect of hypercholesterolemic serum on ZO-1 organization and endothelial permeability. Due to the involvement in the regulation of ZO-1, phosphatidylinositol 3-kinase (PI3K) signaling pathway was also examined.

\section{Material and Methods}

2.1. Hypercholesterolemic Serum Preparation. Rabbits in group A were fed with a $1 \%$ high cholesterol diet and rabbits in group B were fed with normal diet for 4 weeks. Five rabbits' peripheral blood in each group was collected via ear vein. Serum was isolated by centrifugation, respectively, and mixed well for further studies. Total serum cholesterol was measured with an enzymatic timed end-point method automatically. All procedures were in accordance with the guiding principles of Zhejiang University School of Medicine, the principles of the American Heart Association on Research Animal Use, and the Guide for the Care and Use of Laboratory Animals published by the US National Institute of Health (NIH Publication no. 85-23, revised 1996). 
2.2. HUVECs Culture and Treatment. Human umbilical vascular endothelial cells (HUVECs) were prepared as in the previous report [4]. Cells were grown in RPMI-1640 medium (Genom Biomed, China) with 20\% fetal bovine serum (Sijiqing Biological, China) at $37^{\circ} \mathrm{C}$ in a humidified atmosphere of $5 \% \mathrm{CO}_{2}$. Cells were replaced with serumfree medium when they achieved 90\% confluence and were treated with serum-free RPMI-1640 medium (control), different concentration of hypercholesterolaemic serum or combined with PI3K inhibitor wortmannin (Sigma, USA) for 24 hours.

2.3. Western Blot Analysis. Aliquots of cell lysates were separated by $11 \%$ SDS-polyacrylamide gel, and then transferred to nitrocellulose membrane filters. The filters were blocked with TBS-T buffer, containing 20\% skim milk, incubated with a mouse monoclonal antibody to human ZO-1 (1:400) (Zymed, USA) for 2 hours at room temperature, and followed by the addition of goat antimouse $\operatorname{IgG}(\mathrm{H}+\mathrm{L}) / \mathrm{HRP}$ secondary antibody $(1: 10000)$ (Pierce, USA), and ECL (Pierce, USA) visualization of the bands. All tests assayed by western blot were repeated three times. Expression was quantitated by software Quantity-one (Bio-Rad, USA). $\beta$ actin (Santa Crutz, USA) was used as input control.

2.4. RT-PCR. RNA was purified using Minikit (Qiagen, German) according to the manufacturer's procedure and dissolved in $20 \mu \mathrm{L}$ DEPC-treated water. Total RNA of HUVECs was converted into cDNA with oligo dT15 by MMuLV reverse transcriptase (Fermentas, Lithuania). RT-PCR was performed with primers as follows: forward primer: 5' -AAAAGTGAACCACGAGATGCT-3', reverse primer: 5' AAAGGTAAGGGACTGGAGATGA- $3^{\prime}$. The reaction conditions for $\mathrm{ZO}-1$ were $1 \times\left(94^{\circ} \mathrm{C}, 4 \mathrm{~min}\right), 30 \times\left(94^{\circ} \mathrm{C}, 30 \mathrm{~s}\right.$; $\left.51.5^{\circ} \mathrm{C}, 30 \mathrm{~s} ; 72^{\circ} \mathrm{C}, 45 \mathrm{~s}\right)$, and $1 \times\left(72^{\circ} \mathrm{C}, 10 \mathrm{~min}\right)$. PCR products were run in $1 \%$ agarose gel. And the images were analyzed by Kodak Digital Science ID software. $\beta$-Actin was used as the input control.

2.5. Immunofluorescent Staining. Endothelial monolayer was fixed with methanol for 15 minutes at $-20^{\circ} \mathrm{C}$. The monolayer was blocked with $1 \%$ bovine serum albumin (BSA) (Sigma, USA) in TBS-T (20 mM Tris, pH 7.2, and $150 \mathrm{mM} \mathrm{NaCl}$ ), incubated with primary antibody, a mouse monoclonal antibody to human ZO-1, in PBS with $1 \%$ BSA overnight at $4^{\circ} \mathrm{C}$, and followed by incubation with FITC-conjugated secondary antibodies (Pierce, USA) at $37^{\circ} \mathrm{C}$ for 1 hour. Endothelial monolayer was rinsed three times with PBS before being sealed with 50\% glycerol-PBS. Sections were examined by the OLYMPUS BX60 fluorescence microscope at $450 \mathrm{~nm}$.

2.6. Permeability Assay. Endothelial cells were seeded $(100,000$ cells/insert) on gelatin-coated (1\%) polystyrene filters (Costar Transwell, $0.4-\mu \mathrm{m}$ pore size) (Corning, USA), grown to confluence on transwell inserts, and replaced with serum-free RPMI-1640 medium (control), different concentration of hypercholesterolaemic serum or combined with PI3K inhibitor wortmannin for 3 hours. $10 \mathrm{mg} / \mathrm{mL}$ BSA in serum-free medium was added to the upper compartment. Fluid in the lower compartment was the same serum-free medium without BSA. The transfer rate of BSA across the monolayer was assessed by measuring the rise of BSA in the lower well after 30 minutes. BSA was quantified with an Elisa kit.

2.7. Elisa Assay. Elisa assay (Alpha Diagnostic, USA) was performed as instruction. Briefly, $100 \mu \mathrm{L}$ diluted samples were added to each well. Plates were incubated at room temperature for 60 minutes. Plates were washed five times with washing buffer and incubated with $100 \mu \mathrm{L}$ of HRPlabeled antibovine albumin conjugate at room temperature for 30 minutes. Plates were then washed five times with washing buffer and incubated with $100 \mu \mathrm{L}$ of TMB substrate solution at room temperature for 15 minutes. The ELISA was stopped with $100 \mu \mathrm{L} /$ well stop solution and read at OD $450 \mathrm{~nm}$.

2.8. PI3K Activity Assay. The PI3K activity assay was performed as described previously [5]. After treatment of high-cholesterol serum, cells were harvested and the PI3K complexes were pulled down by PI3K antibody. To measure PI3K activity, a TLC-based assay was employed by using phosphatidylinositol 4-5-biphosphate (PIP2) as a substrate. The PI $(3,4,5)$ P3 was quantified by using Molecular Dynamics PhosphorImager. And the phosphorylated products were quantified by excising the spot and scintillation counting (count per minute).

2.9. Statistical Analysis. All statistical calculations were performed with the SPSS 11.5 statistical software package (SPSS Inc). The results were representative of three experiments with different cell preparation in each condition. The data were expressed as mean \pm standard deviation. Results were analyzed by One-Way ANOVA. $P \leq .05$ were considered to be statistically significant.

\section{Results}

3.1. Serum Cholesterol Level after a High-Cholesterol Diet. After 4 weeks of $1 \%$ high cholesterol diet, there was a significant increase in serum cholesterol in tested animals compared with controls $(33.9 \pm 9.4$ versus $1.3 \pm 0.6 \mathrm{mMol} / \mathrm{L}$, $P<.01)$.

3.2. Expression of ZO-1 mRNA and Protein in Hypercholesterolemic-Treated HUVECs. The expression of ZO-1 in endothelial cells after hypercholesterolemic serum (cholesterol concentrations: $0.04,0.08,0.16$, and $0.32 \mathrm{mMol} / \mathrm{L}$ ) exposure was shown in Figure 1(a). The results of RT-PCR revealed that hypercholesterolemic serum could not change the expression of ZO-1 mRNA significantly. Figure 1(b) indicated the effects of hypercholesterolemic serum on ZO-1 protein expression as measured by western blotting. Hypercholesterolemic serum at study concentration treated 

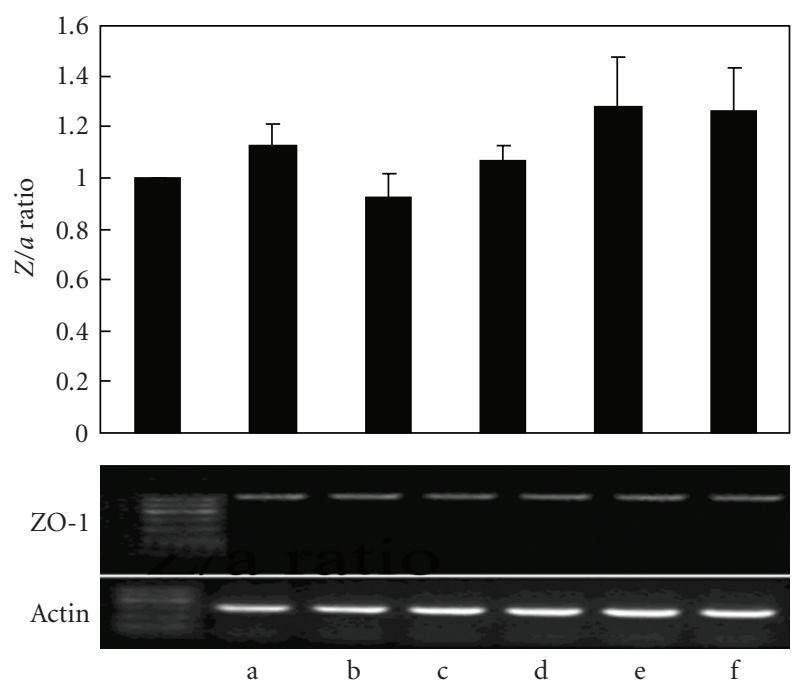

(a)
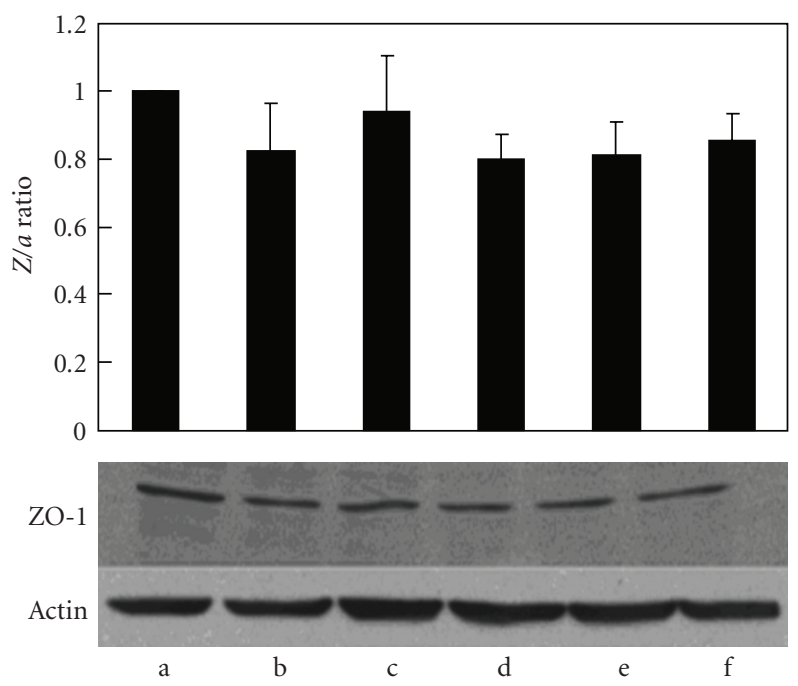

(b)

FIGURE 1: Hypercholesterolemic serum could not change ZO1 expression in mRNA (a) or protein (b) level. a: serum free medium; b: normal rabbit serum; c-f: hypercholesterolemic serum at different cholesterol concentrations. $Z / a$ ratio was calculated as below: the ratio of ZO-1 to actin in control group was regarded as 1 in every test. And $Z / a$ ratio in other groups was adjusted to control group.

for 24 hours could not alter ZO-1 protein expression as compared with the control group (Figure 1).

\subsection{Subcellular Localization of ZO-1 Was Changed by Hyper-} cholesterolemic Serum. The permeability of human endothelial cells is governed in part by the expression and localization of tight junctional proteins as ZO-1. Figure 2 showed the immunofluorescent staining of ZO-1 in HUVECs. ZO-1 in control group was distributed continuously around the periphery of the cells. Compared with the control, the cells exposed to hypercholesterolemic serum showed a loss of junctional ZO-1 localization with subsequent staining. And

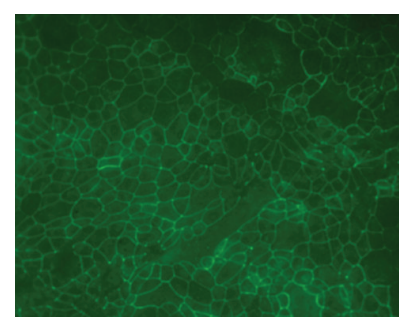

(a)

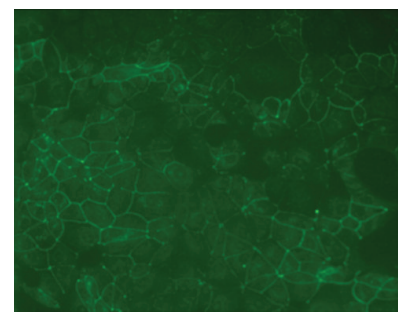

(c)

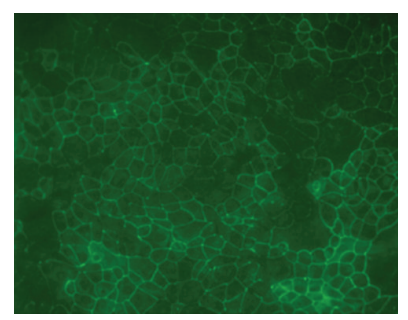

(e)

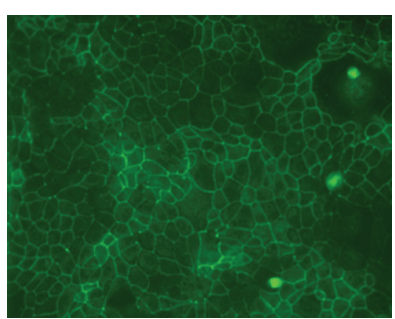

(b)

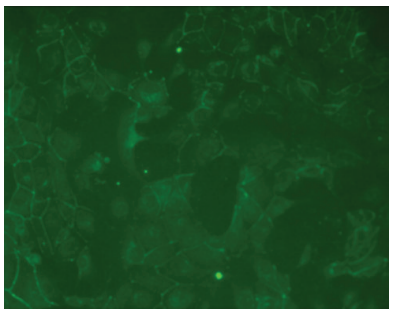

(d)



(f)
FIGURE 2: Hypercholesterolemic serum could alter the distribution of ZO-1 in endothelial cells, which seemed to be dose dependent. PI3K specific inhibitor wortmannin could significantly reverse the effect induced by hypercholesterolemic serum. (a) serum free medium; (b) normal rabbit serum; (c) low concentration of hypercholesterolemic serum $(0.04 \mathrm{mMol} / \mathrm{L})$; (d) high concentration of hypercholesterolemic serum $(0.32 \mathrm{mMol} / \mathrm{L})$; (e) c plus $100 \mathrm{nMol} / \mathrm{L}$ wortmannin; (f) d plus $100 \mathrm{nMol} / \mathrm{L}$ wortmannin.

the dose of hypercholesterolemic serum at study concentrations was positively related with the redistribution of ZO-1 (Figure 2).

3.4. Monolayer Endothelial Permeability Was Increased when Exposed to Hypercholesterolemic Serum. In previous studies, we found that hypercholesterolemic serum could change the distribution of ZO-1 in endothelial cells. To confirm whether hypercholesterolemic serum could change the permeability of endothelial cells, transwell was used to observe the permeability of endothelial cells to BSA. We found that hypercholesterolemic serum could significantly increase the permeability of endothelial cells. The permeability highly depended on the concentration level of hypercholesterolemic serum as shown in Figure 3.

3.5. PI3K Signaling Pathway Was Involved in the ZO-1 Regulation. To investigate the role of PI3K in the regulation of ZO-1, we used both PI3K activity assay and PI3K specific inhibitor wortmannin in the present study. In PI3K activity 


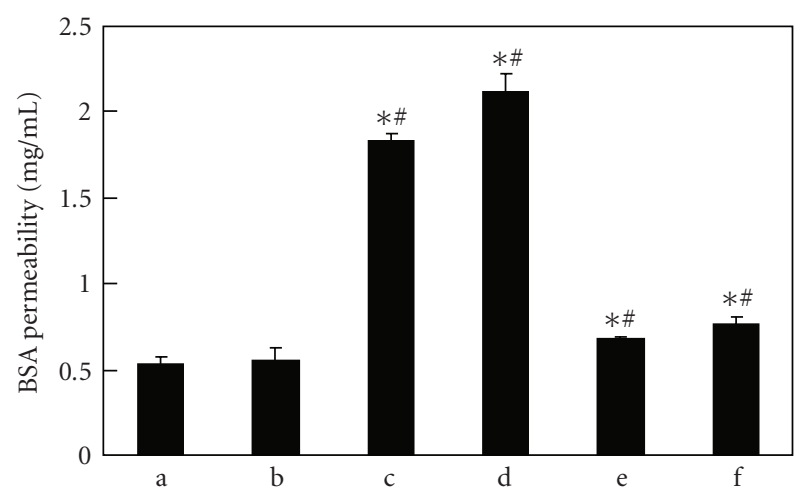

Figure 3: Hypercholesterolemic serum could significantly increase the permeability of endothelial cells, which was detected by albumin permeability test with transwell. And the permeability of endothelial cells increased with the concentration of hypercholesterolemic serum. a: serum free medium; b: normal rabbit serum; c: low concentration of hypercholesterolemic serum $(0.04 \mathrm{mMol} / \mathrm{L})$; d: high concentration of hypercholesterolemic serum $(0.32 \mathrm{mMol} / \mathrm{L})$; e: c plus $100 \mathrm{nMol} / \mathrm{L}$ wortmannin; f: d plus $100 \mathrm{nMol} / \mathrm{L}$. * represents $P<.05$ compared with serum-free medium control; \# represents $P<.05$ compared with previous group.

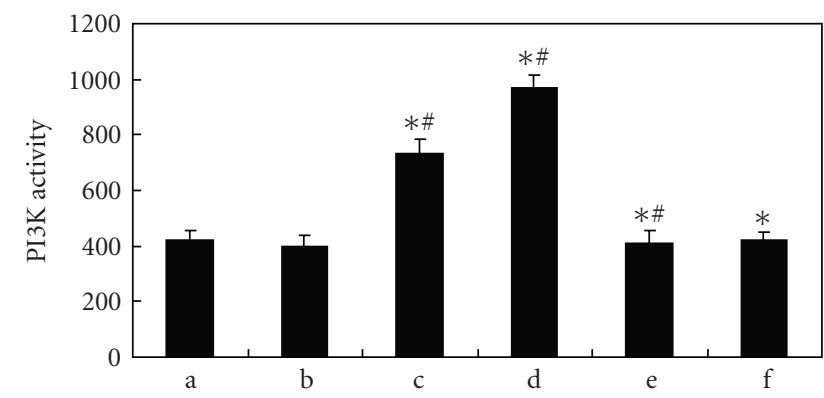

Figure 4: In PI3K activity assay, it was found that hypercholesterolemic serum could significantly enhance PI3K activity with a dose-dependent manner, which could be reversed by wortmannin. a: serum free medium; b: normal rabbit serum; c: low concentration of hypercholesterolemic serum $(0.04 \mathrm{mMol} / \mathrm{L})$; d: high concentration of hypercholesterolemic serum $(0.32 \mathrm{mMol} / \mathrm{L})$; e: c plus $100 \mathrm{nMol} / \mathrm{L}$ wortmannin; f: d plus $100 \mathrm{nMol} / \mathrm{L}$. $*$ represents $P<.05$ compared with serum-free medium control; \# represents $P<.05$ compared with the previous group.

assay, hypercholesterolemic serum is found to increase PI3K activity, which could be reversed with PI3K specific inhibitor wortmannin (Figure 4). And as shown in Figures 2 and 3 , hypercholesterolemic serum induced $\mathrm{ZO}-1$ redistribution and permeability enhancement could be significantly inhibited by $100 \mathrm{nMol} / \mathrm{L}$ wortmannin. So PI3K signaling pathway was undoubtedly involved in the ZO- 1 regulation induced by hypercholesterolemic serum.

\section{Discussion}

Hypercholesterolemia is closely related to the function of vascular endothelial cells [6] and can increase vascular permeability and lead to atherosclerosis [7]. Tight junctions contribute to cell-to-cell contacts in the paracellular cleft and are critical for restricting paracellular diffusion among endothelial cells. So it is suspected that hypercholesterolemia could increase permeability with tight junction-related pathways. However, the relationship between hypercholesterolemia and tight junctions is still unclear. In the present study, we found that hypercholesterolemic serum could alter the distribution of ZO-1 in endothelial cells, but could not change the expression of ZO-1 in both mRNA and protein levels. Due to the limitation of our study, the exact mechanism how hypercholesterolemic serum led to the increasing permeability was not elucidated yet. Some other studies suggested that VEGF might be an interpretation for its capability to rearrange endothelial junctional proteins $[8,9]$. Obviously, further studies are necessary to clarify it.

ZO-1 acts as the scaffold to organize occludin at cell junction sites [10] and links occludin to actin cytoskeleton [11]. The expression and distribution of ZO-1 can significantly influence cell permeability and functions $[3,12]$. In the present study, we found that hypercholesterolemic serum could alter the distribution of $\mathrm{ZO}-1$, while leave the expression of $\mathrm{ZO}-1$ unchanged. In the further permeability assay, we found that the barrier function of endothelium was significantly impaired after being exposed to hypercholesterolemic serum. These results suggested that hypercholesterolemic serum could increase the permeability of endothelial cells through alternation of the distribution of ZO-1. Fischer et al. believed that hyperpermeability induced by $\mathrm{H}_{2} \mathrm{O}_{2}$ was caused by activation of mitogen-activated protein kinase through redistribution of tight junction proteins [13]. PKC signaling pathway was also found to be involved in the regulation of ZO-1. Meanwhile, Sheth et al. found that PI3K signaling pathway was involved in oxidative stress-induced disruption of tight junctions [14]. And in the present study, we found that hypercholesterolemic serum-induced alternation could be significantly attenuated by PI3K specific inhibitor wortmannin, which was further confirmed by the PI3K activity assay. These results revealed that PI3K signal pathway was at least partly involved in the ZO-1 regulation induced by hypercholesterolemic serum.

\section{Conclusions}

In conclusions, our study suggested that hypercholesterolemic serum could alter the distribution of ZO-1 and increase the permeability in endothelial cells, at least partly through PI3K signaling pathway.

\section{Abbreviations}

HUVECs: Human umbilical vascular endothelial cells

PI3K: Phosphatidylinositol 3-kinase

VEGF: Vascular endothelial growth factor

ZO-1: Zonula occludens-1. 


\section{References}

[1] N. T. Collins, P. M. Cummins, O. C. Colgan, et al., "Cyclic strain-mediated regulation of vascular endothelial occludin and ZO-1: influence on intercellular tight junction assembly and function," Arteriosclerosis, Thrombosis, and Vascular Biology, vol. 26, no. 1, pp. 62-68, 2006.

[2] M. Itoh, M. Furuse, K. Morita, K. Kubota, M. Saitou, and S. Tsukita, "Direct binding of three tight junction-associated MAGUKs, ZO-1, ZO-2, and ZO-3, with the COOH termini of claudins," Journal of Cell Biology, vol. 147, no. 6, pp. 13511363, 1999.

[3] J. M. Staddon, K. Herrenknecht, C. Smales, and L. L. Rubin, "Evidence that tyrosine phosphorylation may increase tight junction permeability," Journal of Cell Science, vol. 108, part 2, pp. 609-619, 1995.

[4] C. Bian, J. Lin, X. C. Li, Y. F. Wang, H. Q. Hu, and P. Chen, "Telmisartan-enhanced hypercholesterolaemic seruminduced vascular endothelial growth factor expression in immortalized human umbilical vascular endothelial cells," Scandinavian Journal of Clinical and Laboratory Investigation, vol. 67, no. 6, pp. 619-631, 2007.

[5] Y. Zhu, X. Zhong, S. Zheng, Q. Du, and W. Xu, "Transformed immortalized gastric epithelial cells by virulence factor CagA of Helicobacter pylori through Erk mitogen-activated protein kinase pathway," Oncogene, vol. 24, no. 24, pp. 3886-3895, 2005.

[6] R. Sugano, H. Matsuoka, N. Haramaki, et al., "Polymorphonuclear leukocytes may impair endothelial function: results of crossover randomized study of lipid-lowering therapies," Arteriosclerosis, Thrombosis, and Vascular Biology, vol. 25, no. 6, pp. 1262-1267, 2005.

[7] D. Steinberg, "Thematic review series: the pathogenesis of atherosclerosis. An interpretive history of the cholesterol controversy: part II: the early evidence linking hypercholesterolemia to coronary disease in humans," Journal of Lipid Research, vol. 46, no. 2, pp. 179-190, 2005.

[8] C. G. Kevil, D. K. Payne, E. Mire, and J. S. Alexander, "Vascular permeability factor/vascular endothelial cell growth factor-mediated permeability occurs through disorganization of endothelial junctional proteins," Journal of Biological Chemistry, vol. 273, no. 24, pp. 15099-15103, 1998.

[9] W. Wang, W. L. Dentler, and R. T. Borchardt, "VEGF increases BMEC monolayer permeability by affecting occludin expression and tight junction assembly," American Journal of Physiology Heart and Circulatory Physiology, vol. 280, pp. H434-H440, 2001.

[10] L. L. Mitic and J. M. Anderson, "Molecular architecture of tight junctions," Annual Review of Physiology, vol. 60, pp. 121142, 1998.

[11] B. M. Gumbiner, "Breaking through the tight junction barrier," Journal of Cell Biology, vol. 123, no. 6, pp. 1631-1633, 1993.

[12] S. Esser, M. G. Lampugnani, M. Corada, E. Dejana, and W. Risau, "Vascular endothelial growth factor induces VEcadherin tyrosine," Journal of Cell Science, vol. 111, part 13, pp. 1853-1865, 1998.

[13] S. Fischer, M. Wiesnet, D. Renz, and W. Schaper, " $\mathrm{H}_{2} \mathrm{O}_{2}$ induces paracellular permeability of porcine brain-derived microvascular endothelial cells by activation of the p44/42 MAP kinase pathway," European Journal of Cell Biology, vol. 84 , no. 7, pp. 687-697, 2005.
[14] P. Sheth, S. Basuroy, C. Li, A. P. Naren, and R. K. Rao, "Role of phosphatidylinositol 3-kinase in oxidative stress-induced disruption of tight junctions," The Journal of Biological Chemistry, vol. 278, no. 49, pp. 49239-49245, 2003. 

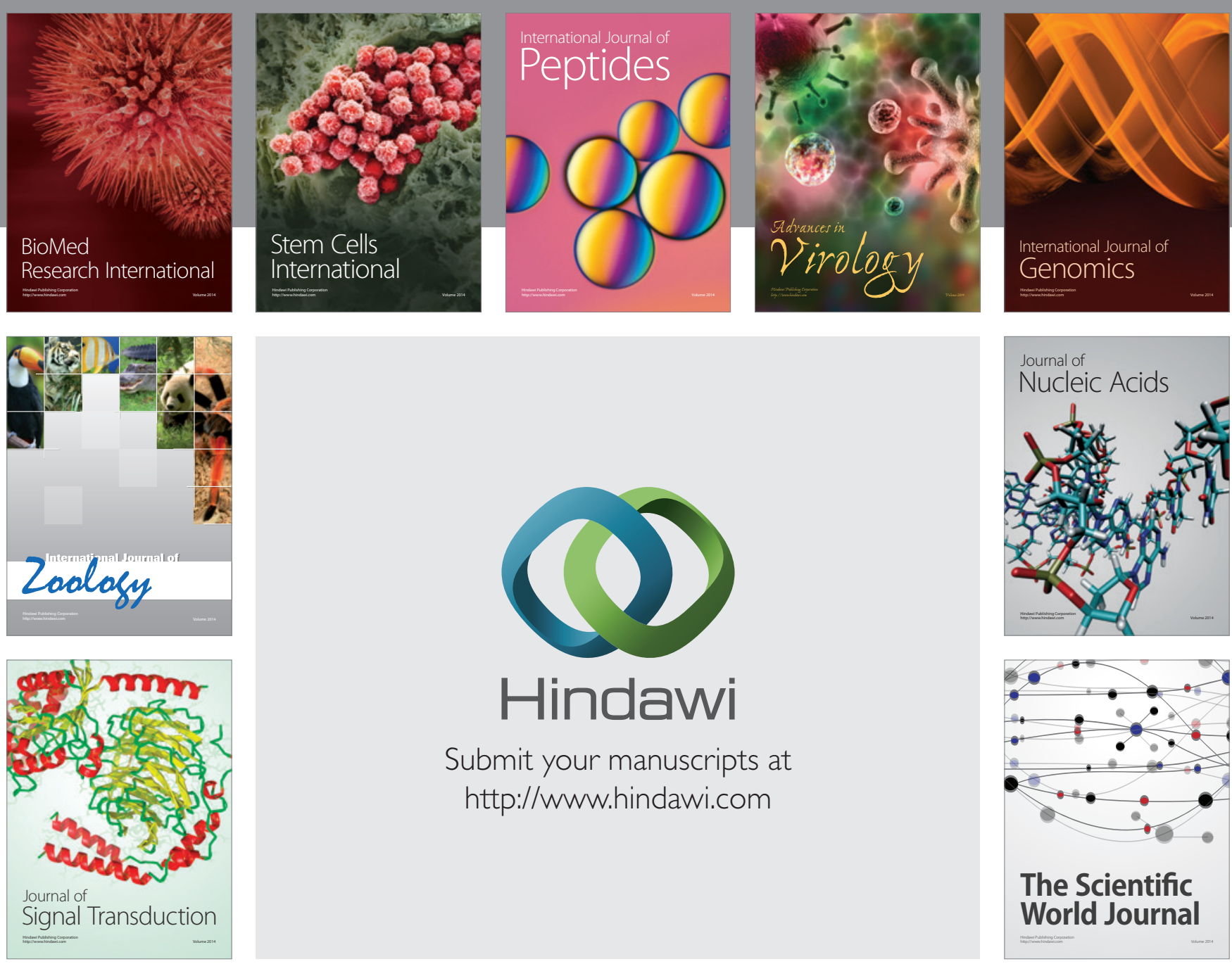

Submit your manuscripts at

http://www.hindawi.com
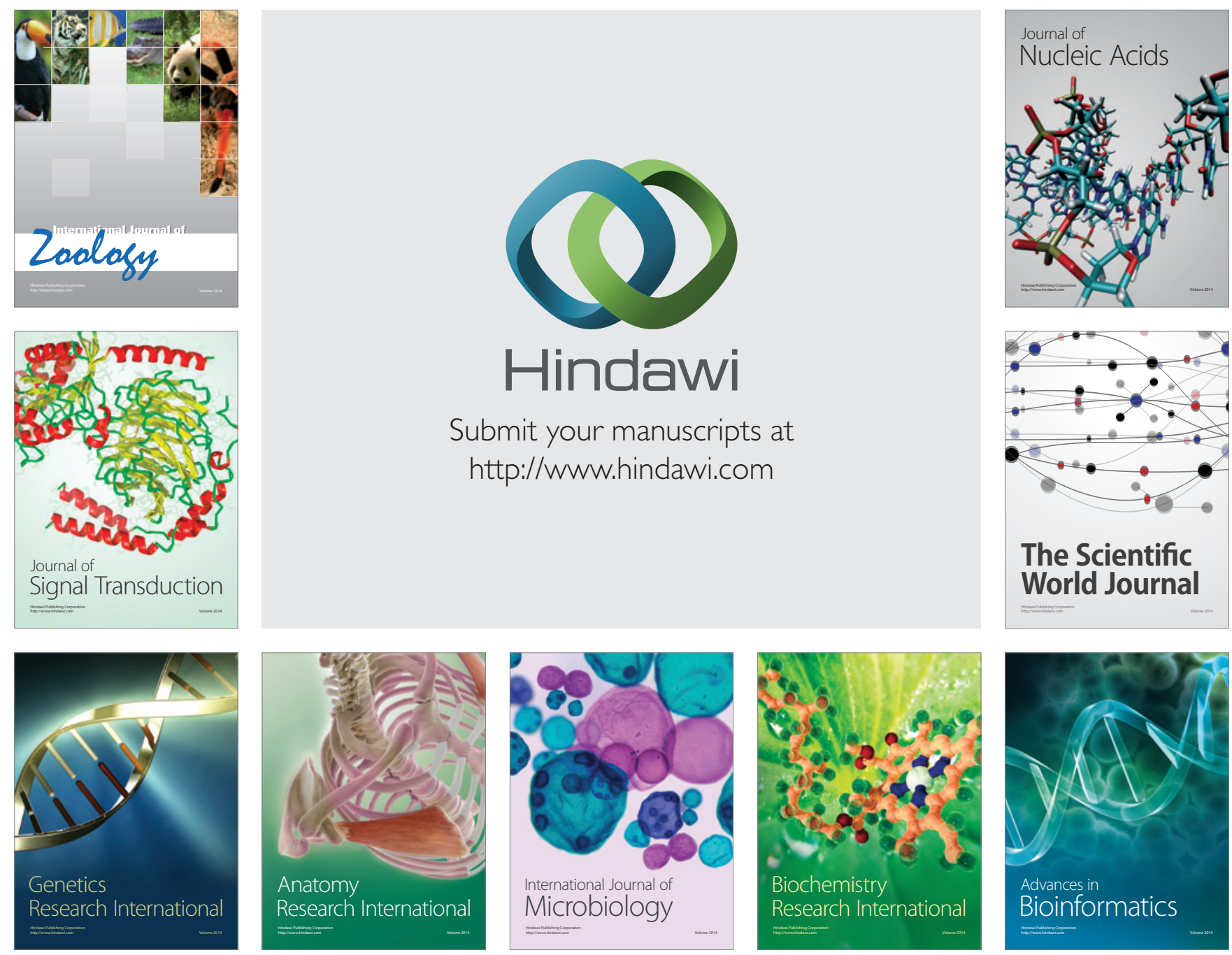

The Scientific World Journal
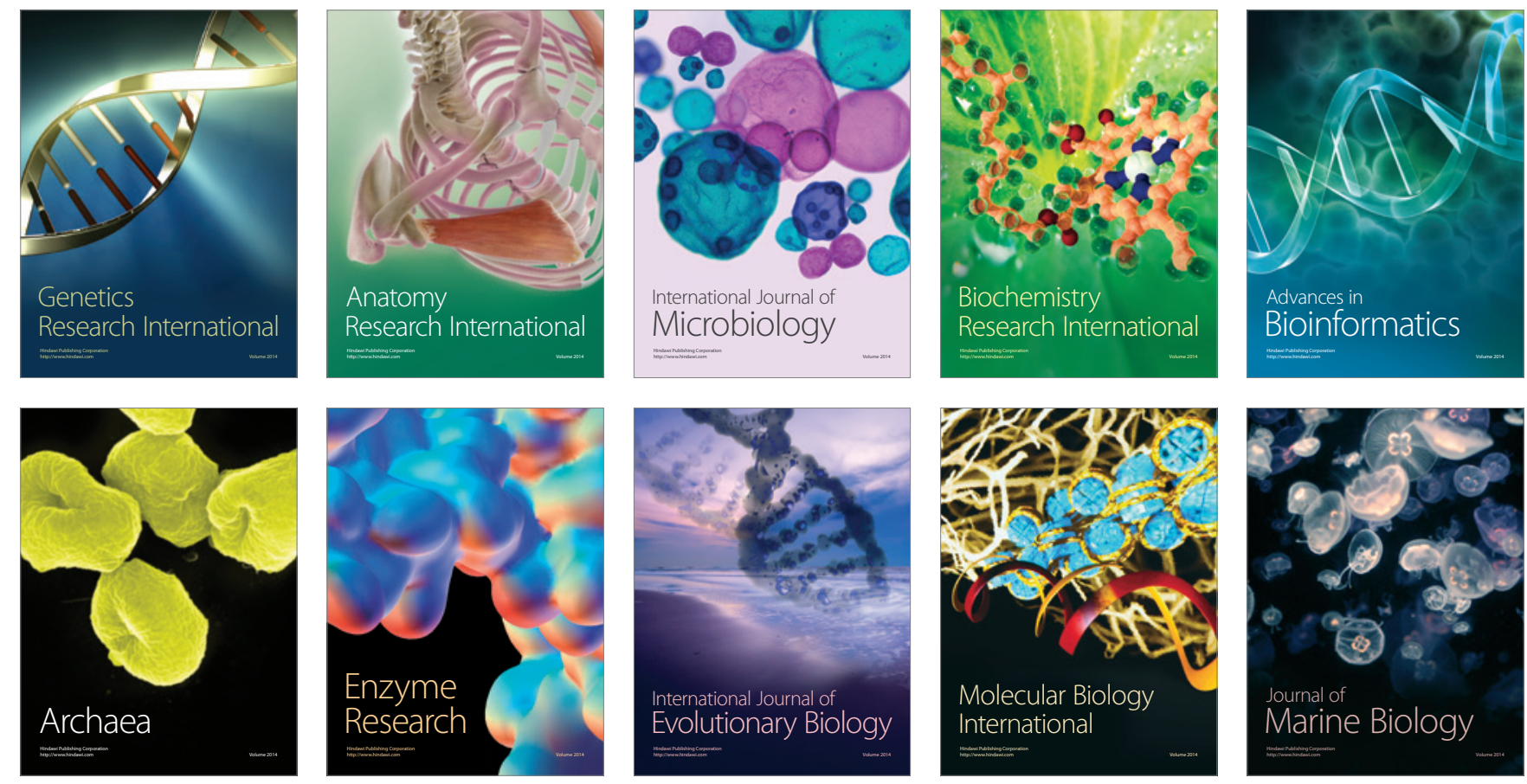